\title{
SCIDOC
}

\author{
International Journal of Dentistry and Oral Science (IJDOS) \\ ISSN: 2377-8075
}

\section{Preference Of Parents Towards The Type Of Topical Fluoride Application For Children With Permanent Dentition}

Research Article

Prathiba Reichal ${ }^{1}$, Vignesh Ravindran ${ }^{2 *}$

${ }^{1}$ Saveetha Dental College and Hospitals, Saveetha Institute of Medical and Technical Sciences (SIMATS), Saveetha University, Chennai- 77, India. ${ }^{2}$ Senior Lecturer, Department of Pediatric and Preventive Dentistry, Saveetha Dental College and Hospitals, Saveetha Institute of Medical and Technical Sciences [SIMATS], Saveetha University, Chennai- 77, India.

\section{Abstract}

Introduction: Topical fluoride application helps in preventing tooth erosion and prevents caries. This fluoride is incorporated with the tooth structure in the form of fluorapatite crystals thereby making the surface more resistant to acid dissolution. Fluoride helps in restricting plaque metabolism, alters plaque composition and reduces the activity of plaque to produce large amounts of acid from carbohydrates.

Materials and Method: the current study was done under a university setting of Saveetha Dental College as a retrospective study. The total sample size after eliminating bias is 917 . Inclusion criteria includes patients with an age group 13-17 years who all underwent topical fluoride application while exclusion criteria includes unclear photographs of fluoride application and error data. SPSS software is used for statistical data analysis with the Chi-square test.

Results and Discussion: The results of the current study shows that parents of both male and female pediatric patients prefer topical fluoride gel $(99 \%)$ application over varnish $(0.9 \%)$. There was no difference in the preference based on gender of the patient ( $\mathrm{p}$-value $>0.05)$.

Conclusion: The current study concludes that parents of both male and female paediatric permanent dentition patients prefer the usage of topical fluoride gel due to its effective post-treatment action.

Keywords: Topical Fluoride; Innovative Method; Permanent Dentition; Dental Caries.

\section{Introduction}

Dental caries is described as one of the chronic diseases all around the world and otherwise it is referred to as tooth decay. This caries develops either in the crown or roots of the tooth and can arise at an early childhood stage thereby affecting the primary dentition of children [1]. These dental caries are caused by the interaction between the acid-producing bacteria, fermentable carbohydrates and other host factors that come in contact with the tooth [2]. It is a kind of biofilm mediated, multifactorial, sugar driven disease that results in demineralisation of the tooth structure and undergoes phases of remineralisation of dental hard tissues [3]. The initiation and progression of dental caries are caused by imbalance in the pathological and protective factors. Dental caries is referred to as a preventable disease with substantial economic and quality of life burdens [4]. Previous studies have documented the substantial decline of caries prevalence among highly industrialised countries around the world with reduction of lifetime caries experience exceedingly more than 75\% [5]. Many articles depicted that the prevalence of dental caries around the world is found to be $60 \%-90 \%$, that is six to nine children out of 10 are affected by dental caries [6]. The progression of caries differs within countries, economic status, education and employment. The progressive destruction of dental tissues is accompanied with severe pain and suffering [7]. This dental caries can be prevented by bringing up slight changes in the diet and nutrition of the individual [8]. It can also be prevented by application of fluoride gel and varnishes [9].

Around the developing countries, application of fluoridated

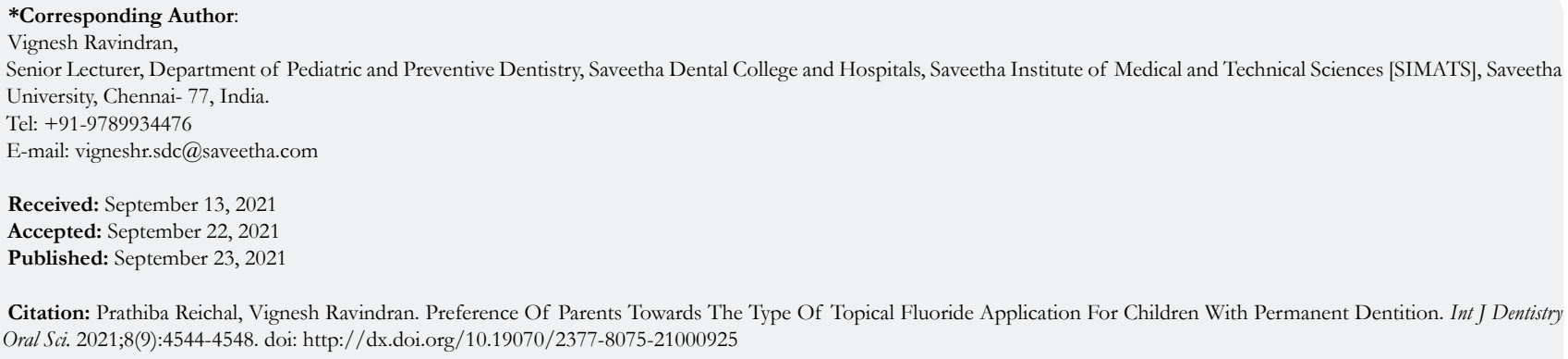

Copyright: Vignesh Ravindran 2021 . This is an open-access article distributed under the terms of the Creative Commons Attribution License, which permits unrestricted use, distribution and reproduction in any medium, provided the original author and source are credited. 
toothpastes was found to reduce the incidence of dental caries and thereby prevent the dental tissues [10]. The use of fluoridated toothpaste came into practise and was officially endorsed by WHO in the 1960's [11]. Fluoride is also added in drinking water for increasing the amount of fluoride in the body. There is a successful reduction in incidence of dental caries in many countries that began from 1940 [12]. Fluoridated salt and water also plays an important role in decreasing the incidence and progression of dental caries [13]. Oral fluoride applicants are of two types. One is biological reservoirs in which fluoride interacts with the bacteria by forming calcium bonds [14]. The other type is mineral reservoirs. This type is known as phosphate contaminated "calcium fluoride like deposit" [15]. The content of fluoride reservoirs are found to be increased through topical fluoride application by using novel procedures [16]. This fluoride therapy is low-cost and is an easily operated treatment that is used to arrest active dental caries [17]. This fluoride is incorporated with the tooth structure in the form of fluorapatite crystals thereby making the surface more resistant to acid dissolution [18]. Fluoride inhibits the process of demineralisation, and enhances the speed of enamel remineralisation along with increase in the mineral content of affected teeth [19]. Fluoride helps in restricting plaque metabolism, alters plaque composition and reduces the activity of plaque to produce large amounts of acid from carbohydrates [20]. Though the complete mechanism of fluoride action is unknown, it is generally acknowledged that fluoride has an effect on the tooth surface.

The other commonly used sources of fluoride are through toothpaste, diet, fluoride supplements, water supply in developed countries, dentifrice, and fluoridated toothpaste and fluoride varnish [21]. Systemically taken fluoride is through fruit juices, carbonated fluoride, infant formulas and certain cereals contain fluoride within them [22]. Previous studies have stated that the application of topical fluoride in combination with the use of fluoridated toothpaste have achieved a modest decrease of dental caries when compared with use of fluoridated toothpaste alone [23]. The application of topical fluoride should be considered only after the overall review of patient general health and vulnerability to diseases. Our team has extensive knowledge and research experience that has translate into high quality publications [24-36, 37-43]. The aim of this study is to analyse the preferences of fluoride application for children with permanent dentition.

\section{Materials and Methods}

The current study was a retrospective study that is conducted under a university setting in the outpatient department of Paediatric and Preventive Dentistry, Saveetha Dental College. The advantages of this study include the population of various strata of society and available data while the disadvantages include the study being unicentric, geographical trends that cannot be assessed. Ethical approval was obtained from the institutional committee (ethical approval number: SDC/SIHEC/DIASDATA). Data that is procured by reviewing patient records and analysed data of patients from June 2019 to February 2021. The total case sheets analysed for the study were $1,52,890$. To eliminate bias, simple random sampling was done to narrow down the sample size to 917 . Verification of the data was done with the presence of additional reviewers procedure notes and photographs of application of fluoride. Stratification and randomisation were done to minimise sampling error. Data that were incomplete were excluded. The obtained data were tabulated in excel systematically. Data were then entered in the SPSS analysis software and descriptive analysis and correlation statistics (chi-square test) were performed. The obtained results were tabulated and graphically represented.

\section{Results}

Among the study participants, $26.9 \%$ and $22.2 \%$ of patients belong to the age of 13 and 17 respectively. $15.7 \%, 16.9 \%$ and $18.2 \%$ of patients are with an age group of 14,15 and 16 (figure 1). Among them $50.6 \%$ and $49.2 \%$ of patients were male and female children respectively while $0.11 \%$ was transgender (figure 2 ). $99 \%$ of patient's parents preferred topical fluoride gel application while $0.9 \%$ of patient's parents preferred topical fluoride varnish application (figure 3). There was no difference in the preference based on gender of the patient (figure 4). Pearson's chi-square test was done and the $\mathrm{p}$-value was found to be 0.266 which was statistically not significant.

\section{Discussion}

The Council of Scientific Affairs (CSA) of the American Dental Association (ADA) issued recommendations for the professional application of topical fluorides for prevention of caries. Topical fluorides are mostly found to be incorporated in toothpaste due to their defensive properties against caries [44]. These fluorides are applied for children whose teeth comprehend certain structural defects or those who exhibit decalcified areas with high risk for caries development. Patients with early childhood caries are highly prone for application of topical fluoride treatment other than fluoridated toothpastes [45]. This accounts for the current study stating that application of topical fluoride is predominantly

Figure 1. The graph represents the age group of the patients with the application of topical fluoride. The $\mathrm{X}$-axis represents the age of the patients while the $\mathrm{Y}$-axis represents the percentage of patients with topical fluoride application. $26.7 \%$ and $22.3 \%$ of patients belong to the age of 13 and 17 respectively. $15.7 \%, 16.9 \%$ and $18.1 \%$ of patients are with an age group of 14,15 and 16.

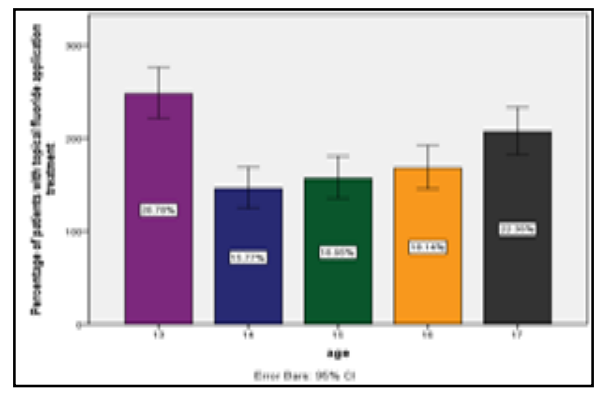


Figure 2. The graph represents the percentage of patients who underwent topical fluoride application in respect to their gender. The $\mathrm{X}$-axis represents the gender and $\mathrm{Y}$-axis represents the percentage of patients with topical fluoride application. $50.9 \%$ and $49 \%$ of patients belong to male and female respectively.

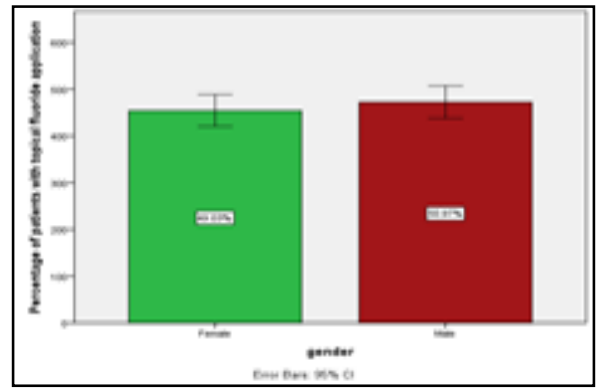

Figure 3. The graph represents the prevalence of type of topical fluoride application treatment. The $\mathrm{X}$-axis represents the different types of fluoride application treatment and $\mathrm{Y}$-axis represents the percentage of prevalence of the type of fluoride application treatment. $\mathbf{9 9 \%}$ of patient's parents preferred topical fluoride gel application that is indicated by blue color while $0.9 \%$ of patient's parents preferred topical fluoride varnish application that is depicted by yellow color.

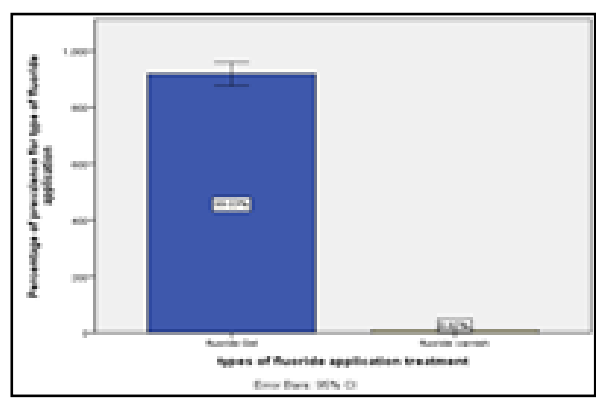

Figure 4. The graph represents the correlation between the percentage of patients with fluoride gel and varnish application with respect to their gender. The $\mathrm{X}$-axis represents the gender of the patients and $\mathrm{Y}$-axis represents the percentage of patients with fluoride application. Blue color indicates the prevalence of parents about the use of topical fluoride gel that was observed to be $48.8 \%$ in female patients and $50.2 \%$ in male patients. Similarly, the preference of parents for the application of fluoride varnish was found to be $0.22 \%$ in female and $0.76 \%$ in male patients. There was minimal difference in the preference based on gender of the patient. Pearson's chi-square test was conducted and the p-value is found to be 0.268 which is statistically not significant.

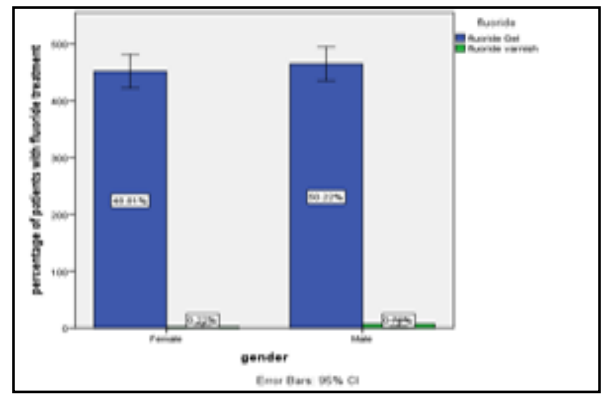

seen in 13 year old children that is followed by 17, 16, 15 and 14 years of age with permanent dentition. Previous studies have reported that parents preferred the use of topical fluoride gel application in children which is found to be the most effective method of preventing early childhood caries than fluoride rinse or varnish [46]. The current study is on par with the former study affirming that fluoride gel application preference is higher when compared to that of fluoride varnish. Application of topical fluoride gel has supplementary advantages since it acts by restoring the minerals to tooth surfaces. Fluorides does not help in removal of caries, rather it creates a strong outer surface over the tooth that prevents the decay from further penetrating into the surfaces [47]. The only disadvantage of topical fluoride gel is the treatment time is 6 minutes whereas for topical fluoride varnish it is 2 minutes. this time consumption is due to the technique of application of fluoride gel using trays [48].
The concentrated form of topical fluoride is referred to as fluoride varnish which has a concentration of $22,600 \mathrm{ppm}(2.26 \%)$ that is applied to tooth structures by using small brushes with sodium fluoride as its active ingredient. The use of fluoride varnish is the application time that is shorter than fluoride gel, since shorter duration procedures are well tolerated by pediatric patients. Similarly, fluoride varnishes can be applied by both dental and non-dental health care professionals with a variety of settings [49]. The only risk factor that is attained in fluoride application is the development of fluorosis where there is an ingestion of fluoride into the developing bone and tooth structures [50]. The other way of application of fluoride is by the over-the-counter fluoride rinse that has a lower concentration of sodium fluoride when compared to gel and varnishes. This rinse is not recommended for children with primary and mixed dentition since there 
is a high risk for swallowing the rinse water and limited ability to rinse and spit [51]. The other risk factor of application of fluoride supplements is fluoride toxicity, that is rarely and particularly seen in children due to ingestion of large quantities of fluoride supplements. The lethal dose of fluoride in children is found to be between 8 and $16 \mathrm{mg} / \mathrm{kg}$ [52].

The advantages of this study imply that this study was performed with available data and population of variant economic stature. The limitations of the study include that it was performed as a unicentric study, smaller sample size, unequal distribution and geographical trends not assessed. Larger sample size and different ethnicity of the participating patients can yield better results. It is also essential to create awareness of the importance of fluoride with respect to various factors such as control early childhood caries, reduce caries risk in children among parents and the general population.

\section{Conclusion}

Within the limits of the present study, fluoride gel was more preferred by the parents of children with permanent dentition. There was no gender based preference noticed. Furthermore studies have to be conducted with increased sample size to affirm this statement with significant statistical data reports.

\section{Acknowledgement}

The authors are thankful to the department of pediatric dentistry, saveetha dental college and Hospitals, Saveetha Institute of Medical and Technical Science, Saveetha University for providing a platform in expressing their knowledge.

\section{Source of Funding}

The present project is funded by:

- Saveetha Institute of Medical and Technical sciences

- Saveetha Dental College and Hospitals

- Saveetha University

- Loyola higher secondary school, cheyyur

\section{References}

[1]. Marinho VC. Applying prescription-strength home-use and professionally applied topical fluoride products may benefit people at high risk for caries - the American Dental Association (ADA) 2013 clinical practice guideline recommendations. J Evid Based Dent Pract. 2014 Sep;14(3):120-3.Pubmed PMID: 25234211.

[2]. Petersen PE, Ogawa H. Prevention of dental caries through the use of fluoride--the WHO approach. Community Dent. Health. 2016 Jun;33(2):66-8. PMID: 27352461.

[3]. Carey CM. Focus on fluorides: update on the use of fluoride for the prevention of dental caries. J Evid Based Dent Pract. 2014 Jun 1;14:95-102.

[4]. Petersen PE, Lennon MA. Effective use of fluorides for the prevention of dental caries in the 21st century: the WHO approach. Community Dent Oral Epidemiol. 2004 Oct;32(5):319-21.

[5]. Gibbons RJ, Houte JV. Dental caries. Annu Rev Med. 1975 Feb;26(1):12136.

[6]. Caries D. Selwitz RH, Ismail AI, Pitts NB. Lancet. 2007;369:51-9.

[7]. Marthaler TM. Changes in dental caries 1953-2003. Caries Res. 2004 MayJun;38(3):173-81.Pubmed PMID: 15153686

[8]. Pitts NB, Zero DT, Marsh PD, Ekstrand K, Weintraub JA, Ramos-Gomez F, et al. Dental caries. Nat. Rev. Dis. Primers. 2017 May 25;3(1):1-6.

[9]. Featherstone JD. Dental caries: a dynamic disease process. Aust Dent J. 2008
Sep;53(3):286-91.

[10]. Ismail AI, Sohn W, Tellez M, Amaya A, Sen A, Hasson H, et al. The International Caries Detection and Assessment System (ICDAS): an integrated system for measuring dental caries. Community Dent Oral Epidemiol. 2007 Jun;35(3):170-8.

[11]. Zero DT. Dental caries process. Dent Clin North Am. 1999 Oct 1;43(4):635-64.

[12]. Al-Ansari MM, Al-Dahmash ND, Ranjitsingh AJA. Synthesis of silver nanoparticles using gum Arabic: Evaluation of its inhibitory action on Streptococcus mutans causing dental caries and endocarditis. J Infect Public Health. 2021 Mar;14(3):324-330.Pubmed PMID: 33618277.

[13]. Kidd EA, Fejerskov O. Essentials of dental caries. Oxford University Press; 2016:2016

[14]. Chauncey HH, Glass RL, Alman JE. Dental caries. Caries Res. 1989;23(3):200-5.

[15]. Wong MC, Glenny AM, Tsang BW, Lo EC, Worthington HV, Marinho VC. Topical fluoride as a cause of dental fluorosis in children. Cochrane Database of Systematic Reviews. 2010(1) ;20;(1):CD007693.

[16]. Richards D. Fluoride gel effective at reducing caries in children. Evid Based Dent. 2015 Dec;16(4):108-9.

[17]. Shah N. Dental caries: the disease and its clinical management. Br. Dent. J. 2009 May;206(9):640.

[18]. Marinho VC, Higgins JP, Sheiham A, Logan S. One topical fluoride (toothpastes, or mouthrinses, or gels, or varnishes) versus another for preventing dental caries in children and adolescents. Cochrane Database Syst Rev. 2004;1.

[19]. Shah S, Bhaskar V, Venkataraghavan K, Choudhary P, Ganesh M, Trivedi $\mathrm{K}$. Efficacy of silver diamine fluoride as an antibacterial as well as antiplaque agent compared to fluoride varnish and acidulated phosphate fluoride gel: an in vivo study. Indian J Dent Res. 2013 Sep-Oct;24(5):575-81.Pubmed PMID: 24355958.

[20]. Davies G. Topical fluoride for preventing caries in children and adults. Dental Nursing. 2010 Jul;6(7):372-6.

[21]. Harris R. Observations on the effect of topical sodium fluoride on caries incidence in children. Aust Dent J. 1959;4:257-60.

[22]. Marinho V. Fluoride gel inhibits caries in children who have low caries-risk but this may not be clinically relevant. Evid Based Dent. 2004 Dec;5(4):95.

[23]. Marinho VC, Higgins JP, Sheiham A, Logan S. Combinations of topical fluorides (varnishes, gels, rinses, toothpastes) versus one topical fluoride for preventing dental caries in children and adolescents. Cochrane Database Syst. Rev. 2000;1.

[24]. Subramanyam D, Gurunathan D, Gaayathri R, Vishnu Priya V. Comparative evaluation of salivary malondialdehyde levels as a marker of lipid peroxidation in early childhood caries. Eur J Dent. 2018 Jan-Mar;12(1):67-70. Pubmed PMID: 29657527.

[25]. Ramadurai N, Gurunathan D, Samuel AV, Subramanian E, Rodrigues SJ. Effectiveness of $2 \%$ Articaine as an anesthetic agent in children: randomized controlled trial. Clin Oral Investig. 2019 Sep;23(9):3543-50.

[26]. Ramakrishnan M, Dhanalakshmi R, Subramanian EMG. Survival rate of different fixed posterior space maintainers used in Paediatric Dentistry - A systematic review. Saudi Dent J. 2019 Apr;31(2):165-172.Pubmed PMID: 30983825.

[27]. Jeevanandan G, Thomas E. Volumetric analysis of hand, reciprocating and rotary instrumentation techniques in primary molars using spiral computed tomography: An in vitro comparative study. Eur J Dent. 2018 JanMar;12(1):21-26.Pubmed PMID: 29657521.

[28]. Princeton B, Santhakumar P, Prathap L. Awareness on Preventive Measures taken by Health Care Professionals Attending COVID-19 Patients among Dental Students. Eur J Dent. 2020 Dec;14(S 01):S105-S109.Pubmed PMID: 33321549.

[29]. Saravanakumar K, Park S, Mariadoss AVA, Sathiyaseelan A, Veeraraghavan VP, Kim S, et al. Chemical composition, antioxidant, and anti-diabetic activities of ethyl acetate fraction of Stachys riederi var. japonica (Miq.) in streptozotocin-induced type 2 diabetic mice. Food Chem Toxicol. 2021 Sep;155:112374.Pubmed PMID: 34186120.

[30]. Wei W, Li R, Liu Q, Seshadri VD, Veeraraghavan VP, Mohan SK, et al. Amelioration of oxidative stress, inflammation and tumor promotion by Tin oxide-Sodium alginate-Polyethylene glycol-Allyl isothiocyanate nanocomposites on the 1,2-Dimethylhydrazine induced colon carcinogenesis in rats. Arab. J. Chem. 2021 Jun 3;14(8):103238.

[31]. Gothandam K, Ganesan VS, Ayyasamy T, Ramalingam S. Antioxidant potential of theaflavin ameliorates the activities of key enzymes of glucose metabolism in high fat diet and streptozotocin - induced diabetic rats. Redox Rep. 2019 Dec;24(1):41-50.Pubmed PMID: 31142215.

[32]. Su P, Veeraraghavan VP, Krishna Mohan S, Lu W. A ginger derivative, zingerone-a phenolic compound-induces ROS-mediated apoptosis in colon cancer cells (HCT-116). J Biochem Mol Toxicol. 2019 Dec;33(12):e22403. 
Pubmed PMID: 31714660 .

[33]. Mathew MG, Samuel SR, Soni AJ, Roopa KB. Evaluation of adhesion of Streptococcus mutans, plaque accumulation on zirconia and stainless steel crowns, and surrounding gingival inflammation in primary molars: randomized controlled trial. Clin Oral Investig. 2020 Sep;24(9):3275-3280.Pubmed PMID: 31955271.

[34]. Sekar D, Johnson J, Biruntha M, Lakhmanan G, Gurunathan D, Ross K. Biological and clinical relevance of microRNAs in mitochondrial diseases/ dysfunctions. DNA Cell Biol. 2020 Aug 1;39(8):1379-84.

[35]. Velusamy R, Sakthinathan G, Vignesh R, Kumarasamy A, Sathishkumar D, Priya KN, et al. Tribological and thermal characterization of electron beam physical vapor deposited single layer thin film for TBC application. Surf Topogr: Metrol Prop. 2021 Jun 24;9(2):025043.

[36]. Aldhuwayhi S, Mallineni SK, Sakhamuri S, Thakare AA, Mallineni S, Sajja R, et al. Covid-19 Knowledge and Perceptions Among Dental Specialists: A Cross-Sectional Online Questionnaire Survey. Risk Manag Healthc Policy. 2021 Jul 7;14:2851-2861.Pubmed PMID: 34262372.

[37]. Sekar D, Nallaswamy D, Lakshmanan G. Decoding the functional role of long noncoding RNAs (lncRNAs) in hypertension progression. Hypertens Res. 2020 Jul;43(7):724-725.Pubmed PMID: 32235913.

[38]. Bai L, Li J, Panagal M, M B, Sekar D. Methylation dependent microRNA $1285-5$ p and sterol carrier proteins 2 in type 2 diabetes mellitus. Artif Cells Nanomed Biotechnol. 2019 Dec;47(1):3417-3422.Pubmed PMID: 31407919 .

[39]. Sekar D. Circular RNA: a new biomarker for different types of hypertension. Hypertens Res. 2019 Nov;42(11):1824-5.

[40]. Sekar D, Mani P, Biruntha M, Sivagurunathan P, Karthigeyan M. Dissecting the functional role of microRNA 21 in osteosarcoma. Cancer Gene Ther. 2019 Jul;26(7-8):179-182.Pubmed PMID: 30905966.

[41]. Duraisamy R, Krishnan CS, Ramasubramanian H, Sampathkumar J, Mariappan S, Navarasampatti Sivaprakasam A. Compatibility of Nonoriginal Abutments With Implants: Evaluation of Microgap at the Implant-Abutment Interface, With Original and Nonoriginal Abutments. Implant Dent. 2019 Jun;28(3):289-295.Pubmed PMID: 31124826.
[42]. Parimelazhagan R, Umapathy D, Sivakamasundari IR, Sethupathy S, Ali D, Kunka Mohanram R, et al. Association between Tumor Prognosis Marker Visfatin and Proinflammatory Cytokines in Hypertensive Patients. Biomed Res Int. 2021 Mar 16;2021:8568926.Pubmed PMID: 33816632.

[43]. Syed MH, Gnanakkan A, Pitchiah S. Exploration of acute toxicity, analgesic, anti-inflammatory, and anti-pyretic activities of the black tunicate, Phallusia nigra (Savigny, 1816) using mice model. Environ Sci Pollut Res Int. 2021 Feb;28(5):5809-5821.Pubmed PMID: 32978735.

[44]. Weyant RJ, Tracy SL, Anselmo TT, Beltrán-Aguilar ED, Donly KJ, Frese WA, et al. Topical fluoride for caries prevention. J. Am. Dent. Assoc. 2013 Nov 1;144(11):1279-91.

[45]. Ritter AV, de Dias WL, Miguez P, Caplan DJ, Swift Jr EJ. Treating cervical dentin hypersensitivity with fluoride varnish. J. Am. Dent. Assoc. $2006 \mathrm{Jul}$ 1:137(7):1013-20.

[46]. Akbar AA, Al-Sumait N, Al-Yahya H, Sabti MY, Qudeimat MA. Knowledge, Attitude, and Barriers to Fluoride Application as a Preventive Measure among Oral Health Care Providers. Int J Dent. 2018 Apr 16;2018:8908924. Pubmed PMID: 29849638.

[47]. Clark MB, Slayton RL. Fluoride use in caries prevention in the primary care setting. Pediatrics. 2014 Sep 1;134(3):626-33.

[48]. Clark MB, Keels MA, Slayton RL. Fluoride Use in Caries Prevention in the Primary Care Setting. Pediatrics. 2020 Dec 1;146(6).

[49]. Maguire A. ADA clinical recommendations on topical fluoride for caries prevention. Evid Based Dent. 2014 Jun;15(2):38-9.

[50]. Newbrun E. Current regulations and recommendations concerning water fluoridation, fluoride supplements, and topical fluoride agents. J Dent Res. 1992 May;71(5):1255-65.Pubmed PMID: 1607443.

[51]. Osuji OO, Leake JL, Chipman ML, Nikiforuk G, Locker D, Levine N. Risk factors for dental fluorosis in a fluoridated community. J Dent Res. 1988 Dec;67(12):1488-92.Pubmed PMID: 3198847.

[52]. Mascarenhas AK. Risk factors for dental fluorosis: a review of the recent literature. Pediatr Dent. 2000 Jul 1;22(4):269-77. 